\title{
Hypothyroidism as a cause for nephrotic syndrome: Two case reports
}

\author{
Amarasinghe $\mathrm{A}^{1}$,Janya $\mathrm{J}^{2}$,Jayawardena $\mathrm{H}^{3}$,Jayanaga $\mathrm{A}^{4}$
}

\section{Introduction}

Nephrotic syndrome (NS) in adults needs the presence of proteinuria $>3.5 \mathrm{~g} / 24 \mathrm{~h}$, hypoalbuminemia $(<3$ $\mathrm{g} / \mathrm{dL}$ ), peripheral edema and often hyperlipidemia for complete diagnosis. The NS may occur in a wide variety of primary and systemic diseases. In adults, the main causes are primary glomerulonephritis (in particular membranous nephropathy and focal segmental glomerulosclerosis), and $30 \%$ of cases are due to a systemic disease such as diabetes mellitus, systemic lupus erythematosus or amyloidosis. 1

Hypothyroidism, is a recognized complication of nephrotic syndrome. ${ }^{2}$ This is secondary to loss of protein in the urine and increased urinary excretion of thyroid hormones and thyroxine-binding globulin. The exact prevalence of hypothyroidism and subclinical hypothyroidism in adult patients with nephrotic proteinuria is not known. ${ }^{2}$ However hypothyroidism as a cause for nephrotic syndrome is debatable.

We describe two patients with untreated hypothyroidism who presented with nephrotic range proteinuria and features to suggest nephrotic syndrome.

\section{Case 1}

36-year-old woman presented with generalized swelling. She was normotensive and had an unremarkable past medical history. Her Hemoglobin was $9.9 \mathrm{~g} / \mathrm{dL}$. Iron studies confirmed iron deficiency. Her serum creatinine was $0.86 \mathrm{mg} / \mathrm{dL}, \mathrm{C}$ reactive protein was $<6 \mathrm{mg} / \mathrm{L}$. HbA1C was $5.9 \%$, serum albumin 2.1 $\mathrm{mg} / \mathrm{dL}$ and INR 1.1. Echocardiogram revealed good ventricular function. Her urine protein creatinine ratio (UPCR) was 15.72 (<0.2). Her TSH was $109 \mathrm{mlU} / \mathrm{L}$ and $\mathrm{T} 4<0.1 \mathrm{ng} / \mathrm{dL}$. ANA titre was insignificant(1:80). Complements C4 $10 \mathrm{mg} / \mathrm{dL}$ (15-45), C3 $116 \mathrm{mg} / \mathrm{dL}$ (88-201). cANCA and pANCA was not detected. Se-

\footnotetext{
1,3,4 National Hospital, Sri Lanka

2,National Hospital, Sri Lanka

Faculty of Medicine, University of Sabaragamuwa
}

Corresponding Author:

Amanda Amarasinghe

Email: amathathsarani99@gmail.com

(iD) https://orcid.org/0000-0002-6352-208X rum cryoglobulin was negative. Anti-thyroid peroxidase antibody was present $>100 \mathrm{IU} / \mathrm{mL}$ (>30). Contrast tomogram of neck, chest, abdomen and pelvis failed to show any evidence of a malignancy. Ultra sound scan of breast and mammogram were normal. Her renal biopsy showed mild mesangial hyper cellularity with minimal tubulointerstitial changes. There was no leucocyte infiltration and blood vessels were normal. The immunofluorescence failed to reveal any significant staining. She was started on prednisolone as per nephrologist's advice along with thyroxine. She responded well to treatment with reduction in UPCR.

\section{Case 2}

32-year-old woman was admitted for evaluation of proteinuria by the renal unit. She had normal blood pressure and bland urinary sediment. Her past medical history has been unremarkable. Her hemoglobin was $11.5 \mathrm{~g} / \mathrm{dL}$ and ESR $60 \mathrm{~mm} / \mathrm{hr}$. Fasting blood sugar was $80 \mathrm{mg} / \mathrm{dL}$. Her Serum creatinine was $0.8 \mathrm{mg} / \mathrm{dL}$, serum albumin $2.1 \mathrm{~g} / \mathrm{dL}$, INR 1.2 and UPCR was 10.08 . her serum cholesterol was $366 \mathrm{mg} / \mathrm{dL}$. ANA and ANCA were negative. Her complements C3 was 74 $\mathrm{mg} / \mathrm{dL}$ (88-201) and C4 $26 \mathrm{mg} / \mathrm{dL}$ (15-45). Hepatitis $B, C$ and HIV screening tests were negative. Her TSH was $>150 \mathrm{mIU} / \mathrm{L}$ and T4 was $<0.10 \mathrm{ng} / \mathrm{dL}$. Her renal biopsy showedmoderate thickening of the basement membranes and silver stain highlights the membrane thickening with spikes. All sampled glomeruli showed mesangial expansion.Immunofluorescence showed granular staining with IgG in glomerular capillary walls and mesangium suggestive of membranous glomerulopathy. She was started on Irbesartan, frusemide and thyroxine.She improved with treatment and was referred to renal clinic for follow up.

\section{Discussion}

Our patients had bland urine sediment and nephrotic range proteinuria and fulfilled clinical criteria for diagnosis of NS. The inflammatory markers, C3/C4 and antinuclear antibodies (ANA) were normal. Further investigations failed to elucidate a secondary cause for NS such as Hepatitis B and C, HIV, systematic lupus erythematous, diabetes or plasma cell dyscrasias and solid malignancy. In both patients' serum creatinine remained normal. It is prudent to consider the pos- 
sibility that the proteinuria could be a result of hypothyroidism.

Hypothyroidism results in many metabolic effects, such as dyslipidemia, hypertension, accelerated atherosclerosis. Hypothyroidism affects the renal physiology by affecting the renal blood flow, vascular resistance, and tubular function. Recent studies have shown hypothyroidism is associated with decreased estimated renal function and proteinuria. 3 Whether this proteinuria is severe enough to cause nephrotic syndrome is not clear.

Hypothyroidism has been found to be associated with glomerular pathologies, such as membranous glomerulopathy (MN), minimal change disease (MCD), and membranoproliferative glomerulonephritis (MPGN). ${ }^{4,5}$

Renal histology in case (1)showed a mesangial expansion with minimal tubule interstitial changes. It fall short of a conclusive diagnosis as the immunofluorescence was negative. In case 2 histology was clearly suggestive of membranous glomerulopathy. In view of the presence of mesangial proliferation a secondary cause should be considered. Hypothyroidism can very well be the secondary cause.

According a recent pathological evaluation in 260 patients, renal histology varied with the thyroid dysfunction in patients with NS.Among the patients with subclinical hypothyroidism, MN was the most common pathologic type (40.4\%), followed by MCD (28.1\%). In the hypothyroidism group MCD was the leading pathologic type, consisting of $48.8 \%, \mathrm{MN}$ in $33.3 \%$ respectively. In contrast the low $\mathrm{T} 4$ normal TSH group, $80 \%$ of the patients were focal segmental glomerular sclerosis (FSGS). ${ }^{6}$

Elevated serum creatinine and reduced glomerular filtration rate have been associated with subclinical hypothyroidism. ${ }^{7}$ The pathophysiological mechanisms underlying this association were thought to be the decline of renal plasma flow, promoted by the imbalance between stroke volume and peripheral resistance.

Abnormal thyroid function is a recognized complication of nephrotic diseases. Changes in thyroid hormones in NS has been explained by the loss of hormone binding proteins in urine. FT4 is usually mostly reabsorbed by the tubules, while FT3 is just secreted most studies have confirmed the high excretion of T4 and T3 in NS. There is a negative correlation with serum albumin level and TSH among patients with NS. Furthermore, there is a positive correlation between $24 \mathrm{~h}$ proteinuria and urinary concentration of T4, T3 and TBG. ${ }^{8}$ However hypothyroidism in NS cannot be explained by the substantial urinary excretion of T4, T3 and TBG alone. According to recent reports most patients with NS have subclinical hypothyroidism, when the thyroid is able to compensate for the urinary loss of hormones and patients remain euthyroid. However, if a primary glandular disease coexists, overt hypothyroidism can develop. ${ }^{9}$

Hypothyroidism as a cause for NS has been investigated as early as in 1926. Albert A. Epstein has postulated a common etiology for hypothyroidism and nephrotic state. ${ }^{10}$ However it was found out that LT4 alone was ineffective in the treatment of proteinuria, oedema and associated hypercholesterolemia in nephrotic syndrome. ${ }^{11}$

Recent report from Sri Lanka described two cases of severe hypothyroidism presenting with elevated serum creatinine and proteinuria, which normalized on treatment with thyroxine alone. ${ }^{12}$

It has been shown that subclinical hypothyroidism and is an independent predictor of renal outcomeif a nephrotic glomerular disease is accompanied by hypothyroidism.Thus normalising TSHconcentrations with replacement of LT4 therapy preserves renal function in patients with a kidney disease. Coexistent hypothyroidism may exacerbate fluid retention of NS, which may be difficult to resolve without LT4 therapy. ${ }^{13}$

\section{Conclusion}

The increased prevalence of hypothyroidism and sub-clinical hypothyroidism in patients with proteinuria is well recognized. The relative pathophysiological mechanisms of renal-thyroid interplay is not completely understood. However we feel that thyroid function assessment should be a part of routine investigation work-up of a patient presenting with nephrotic syndrome or significant proteinuria.

\section{References}

1. Hull RP, Goldsmith DJ. Nephrotic syndrome in adults. BMJ. 2008; 336(7654):1185-1189.

2. Feinstein El, Kaptein EM, Nicoloff JT, et al. Thyroid function in patients with nephrotic syndrome and normal renal function. Am J Nephrol. 1982; 2: 7076.

3. Chang YC, Chang $\mathrm{CH}$, Yeh YC, Chuang LM, Tu YK. Subclinical and overt hypothyroidism is associated with reduced glomerular filtration rate and proteinuria: a large cross-sectional population study. Sci Rep. 2018;8(1):2031.

4. Iwazu Y, Nemoto J, Okuda K, Nakazawa E, Hashi- 
moto A, Fujio Y, Sakamoto M, Ando Y, Muto S, Kusano $E$. A case of minimal change nephrotic syndrome with acute renal failure complicating Hashimotos disease. Clin Nephrol. 2008;69(1):47-52.

5. Valentin M, Bueno B, Gutierrez E, Martinez A, Gonzalez E, Espejo B, Torres A. Membranoproliferative glomerulonephritis associated with autoimmune thyroiditis. Nefrologia. 2004;24(Suppl 3):43-8.

6. Ling-Zhi Li, Yao Hu, shuang-Lan Ai, Lu Cheng, Jing Liu, emily Morris, et al. The relationship between thyroid dysfunction and nephrotic syndrome: a clinicopathological study. Nature.research 2019 April (9) 1

7. El Ters M, Patel SM, Norby SM. Hypothyroidism and reversible kidney dysfunction: an essential relationship to recognize. EndocrPract. 2014; 20:490-499.

8. Burke CW, Shakespear RA. Triiodothyronine and thyroxine in urine. II. Renal handling, and effect of urinary protein. J Clin Endocrinol Metab. 1976; 42: 504-513.

9. Iglesias P, Diez JJ. Thyroid dysfunction and kidney disease. Eur J Endocrinol. 2009; 160: 503-515.

10. Epstein AA. Thyroid therapy and thyroid tolerance in chronic nephrosis. JAMA. 1926; 87: 913.

11. Recant L, Riggs DS. Thyroid function in nephrosis. J Clin Invest. 1952; 31:789.

12. Weerakkody RM, Lokuliyana PN. Severe hypothyroidism presenting as reversible proteinuria: two case reports Journal of Medical Case Reports (2019) 13:270

13. Shin DH, Lee MJ, Seung JK. Preservation of renal function by thyroid hormone replacement therapy in chronic kidney disease patients with subclinical hypothyroidism. J Clin Endocrinol Metab. 2012; 97:2732-2740 